\title{
Leprosy control in a Primary Health Care programme in the Sudan
}

\author{
A H HAYDAR \\ Leprosy Department, Department of Epidemiology, Ministry of \\ Health, Sudan
}

Received for publication 15 December 1982

\section{Introduction}

Over the last 3 decades there have been marked changes in leprosy control policies. Until the early 1940's the practice had been the compulsary segregation of leprosy patients in colonies. ${ }^{1}$ This was later replaced by their treatment in leprosy villages. ${ }^{2,3}$

Before the introduction of the sulphone drugs, isolation was the main method of leprosy control. After the introduction of sulphone ${ }^{4}$ and the proved effectiveness of dapsone by mouth ${ }^{5}$, there was a marked inclination towards outpatient treatment. Some leprologists ${ }^{6,7}$ called for caution in respect to the policy of giving up isolation for outpatient treatment. However, the results of $^{8,9,10}$ proved beyond doubt the efficiency of chemotherapy in reducing infectivity of lepromatous patients and that there was no need for isolation of the leprosy patients. This breakthrough in the leprosy treatment was also a potent therapy for the social pathology of the disease. ${ }^{11}$

Over the years control programmes undertaken in different countries varied widely. ${ }^{12}$ Vertical leprosy control programmes, integrated programmes, or partially integrated programmes were developed in different countries. ${ }^{13}$ However, many leprosy workers were in favour of an integrated programme as a better method for the control of leprosy. ${ }^{14}$

The concept of integration of leprosy control into the general health services

Integration is defined as 'a series of operations concerned in essence with the bringing together of otherwise independent administrative structures, functions 
and mental attitudes in such a way as to combine these into a whole'. ${ }^{15}$ The WHO expert committee ${ }^{16}$ stated that leprosy should not be considered as a disease apart but as a general public health problem in countries where it is endemic. This was further stressed in the WHO expert committee report ${ }^{17}$ which mentioned that the outpatient treatment of leprosy should be carried out in the health centre which also deals with general health of the community.

Browne $^{18}$ gave medical, economic, operational, social and administrative reasons for integration, whilst Schaller ${ }^{19}$ stressed the economical shortcomings as the most important reasons for integration. There is no doubt that the economic factor is among the most important and decisive factors in most developing countries. Hasselblad ${ }^{20}$ described a vertical health delivery system as a luxury which can be afforded only by few countries. He also stressed the side effects of the stigma associated with leprosy as another important reason for integration. He stated that leprosy will never become a disease 'like any other' so long as it is treated in isolation. Health education can never overcome the stigmatizing attitudes with which the community regards leprosy so long as the medical profession itself gives support to 'separate' methods of control.

For many leprologists ${ }^{14,21,22}$ integration could be the only way to tackle the problem of leprosy. However, with the wide diversity of health delivery systems in different countries, a generalization would not be practical. When to integrate and how to integrate will depend on the degree and development of the health services in the country and its future plans for development. ${ }^{23}$

\section{Leprosy control and the primary health care programme in the Sudan}

Leprosy is a public health problem in the Sudan. The prevalence rate varies widely in the different provinces. Leprosy control activities are mainly through leprosy settlements established in the 1940's and a few mobile units run by the missionaries. A few leprosy patients are seen in the dermatological clinics and some outpatient clinics.

In 1974 the Government of the Sudan decided to develop a national health programme within the context of the National Socioeconomic Plan for the period 1977-84. With the assistance of WHO a National Health Programme document was made where 15 health problems were selected according to certain criteria as priority problems. In the final analysis, 8 of the 15 problems were grouped under the heading of Primary Health Care (PHC), which was singled out as the most important field for government action during the development plan for $1977-84 .^{24}$

During the years $1975-76$ a detailed PHC programme document was prepared for each of the 5 regions of the Sudan. ${ }^{25,26}$ The main objective of the programme is maximum coverage whereby PHC should become accessable to the entire population by 1984 . The programme stressed the concept of 
community-based services and gives particular attention to the preventive and promotive aspects of health.

The delivery of service is planned through a network of Primary Health Care Units (PHCU). Each PHCU serves a population of 4,000 people within a radius of 10 miles (these parameters are now under revision). The PHCU is staffed by a Community Health Worker (CHW), who is an indigenous member of the community, selected by the community, and paid by the local council. $\mathrm{He}$ is given 9 months training to enable him to diagnose and treat a limited number of diseases and to be able to suspect a further group of diseases (including leprosy) and to refer to a dispensary or hospital for confirmation of diagnosis and initiation of treatment. It is his duty to carry out the treatment prescribed for the patients by a medical assistant or a medical officer and he should keep the patients' records. Being from the same community he can examine contacts of patients and give health education to the people on appropriate subjects.

For each five PHCU there is a dispensary staffed by a medical assistant (a nurse with a further 2 years training in a medical assistant school). The medical assistant confirms the diagnosis of leprosy, initiates treatment, and refers the patient back to continue his treatment at home under supervision of the $\mathrm{CHW}$. He could also examine contacts and carry out school surveys in his area. Where he fails to confirm the diagnosis he refers the patient to the medical officer in the rural hospital, who may confirm the diagnosis or refer the patients to the dermatologist at the provincial hospital.

The importance of training for leprosy control activities has always been stressed. ${ }^{13,27-29}$ Training is becoming more important with the increasing magnitude of the drug resistance problem ${ }^{30}$ and the need to use multiple drug regimens.

To ensure that leprosy control activities in the Sudan are carried out effectively through an integrated programme, specific training in leprosy control is necessary for all professional and auxiliary staff. Indeed, training is considered as the key to the success of the control programme and is given high priority in planning. Leprosy is included in the curriculum of the medical schools. Lectures are given on leprosy as a tropical disease and the disease is also tackled as a public health problem. A national leprosy training centre has already been established at Wau and gives training for different categories of auxiliary staff. Priority in training is given to the tutors of the different training institutes and the medical assistants from highly endemic areas.

Monthly and annual reports are written by the different health units and operational and epidemiological evaluation is carried out at the provincial, regional and central levels.

Supervision is essential and is carried out by the senior staff responsible for the other health activities (Assistant Commissioner for Health, Provincial Medical Assistant etc). It has been noticed that the specialized leprosy worker 
(a leprosy supervisor) is unable to supervise the medical assistants in the dispensaries because he is administratively junior to them.

\section{Discussion}

An integrated leprosy control programme has been carried out successfully in USSR $^{31}$ where leprosy patients were seen in all specialized health units, sanitary epidemiologic stations and rural medical units. Integration was also tried in Indonesia ${ }^{32,33}$ where there is low leprosy endemicity, economic difficulties and scarcity of qualified personnel. In Indonesia, use was made of the existing facilities, personnel, institutes and equipment. It was shown ${ }^{33}$ that efficient case finding is possible through the use of non-specialized paramedical personnel. In Venezuela, the leprosy field units were integrated into the Ministry's regional medical centre. ${ }^{34}$ In Brazil, integration was carried out on a pilot project basis ${ }^{35}$ and encouraging results were reported.

The Sudan is one of the poor developing countries with many health problems and scarce resources. Leprosy, though a big public health problem, is not the first or second priority; there are several other more pressing health problems. ${ }^{36}$ Until recently, leprosy control activities have remained confined mainly to the leprosy settlements where the patients have little medical care.

Through an integrated programme it becomes feasible to cover the whole country and to provide adequate regular chemotherapy for all detected cases. Case-finding and contact surveillance could be carried out by the CHW. The leprosy patients will have access to all the existing health facilities and will share with their fellow-citizens the available resources. The programme will also provide the necessary treatment for the patient near to his home and within his community.

In the Sudan, as in many countries there is a strong stigma associated with leprosy. ${ }^{37}$ As the leprosy patient is not accepted in his community and was usually sent to one of the settlements, patients tend to hide till they are deformed. Through an integrated programme the stigma associated with the disease could be lessened as experienced in Thailand. ${ }^{38}$

\section{Conclusion}

An integrated leprosy control programme is of much benefit to the individual leprosy patient, to his family and to the whole community. It is a suitable system for developing countries with scarce financial and other resources like the Sudan. It is both economical and feasible. However, the results of an integrated approach to leprosy control within the framework of PHC in the Sudan 
remain to be evaluated. Constant evaluation and appraisal are vital elements in the concept of PHC.

\section{Acknowledgements}

I am grateful to Dr Ali Ahmed Idris and Dr Ali Biely for reading the manuscript and for their valuable comments. I would like also to thank Mrs Hayat Hussein for typing the paper.

\section{References}

${ }^{1}$ Winter PD. South Africa Leprosy Law and control policy. Int. J. Lepr 1949; 17: 253-63.

2 Bloss JFE. The control of leprosy among the Azards Anglo Egyptian Sudan. Trans Roy Soc Trop Med Hyg, 1964; 39: 5, 423-36.

${ }^{3}$ Davey TF. Decline of leprosy in a group of Nigerian villages between 1941 and 1956. Int $J$ Lepr, 1957; 25: 4, 329-44.

${ }^{4}$ Faget GH, Pogge RC, Johansen FA, Dinan JF, Prejean BM, Eccles CG. The promin treatment of leprosy. A progress report, 1944. Reprinted Int J Lepr, 1966; 34: 3, 298-310.

${ }^{5}$ Lowe J. Sundry experience in the chemotherapy of leprosy. Int J Lepr, 1951; 19: 1, 15-21.

${ }^{6}$ Dharmendra. Need for a balanced approach to leprosy control. Int J Lepr, 1965; 33: 2, 232-40.

${ }^{7}$ Schujman S. Value of segregation of bacteriologically positive cases in the prophylaxis of leprosy. Int J Lepr, 1963;31: 1,46-52.

${ }^{8}$ Figueredo N, Balkrishnan V. Risk of infection in leprosy. Lepr Rev, 1967; 28: 2, 87-92.

9 Worth RM. Is it safe to treat leprosy patients at home? A study of house exposure to leprosy in Hong Kong. Int J Lepr, 1968; 36: 296-302.

10 Worth RM, Wong KO. Further notes on the incidence of leprosy in Hong Kong. Children living with a lepromatous parent. Int J Lepr, 1971; 39: 3, 745-9.

11 Long ER. The social stigma of disease. Int J Lepr, 1965; 33: 1, 98-102.

12 Ross Innes J. Co-ordination of methods of leprosy control. Int J Lepr, 1958; 26: 2, 145-7.

13 Browne SG. The training and development of medical auxiliary in the leprosy campaign. Ann Trop Med Parasit, 1975; 69: 4, 413-16.

14 Cochrane RG. Leprosy in Theory and Practice. John Wright Bristol, 1959.

15 WHO. In tegration of mass campaign against specific diseases into general health service. Technical Report Series, 1962; 294: 5 .

16 WHO. Expert Committee on Leprosy: First report. Technical Report Series, 1953; 71 : 28.

17 WHO. Expert Committee on Leprosy: Technical Report Series, 1966; 319.

18 Browne SG. The integration of leprosy control into the general health services. Lepr Rev, 1972; 43: 16-20.

19 Schaller KF. Integration of leprosy control in to the health centre scheme. Lepr Rev, 1969; 40: 243-8.

20 Hasselblad OW. The management of leprosy in comprehensive community health planning. Int J Lepr, 1971;39: 2, 183-4. 
21 Ekambaram, Vand Sharma CSG. Leprosy relief and control work in Tirukoilur, South India. Lepr Rev, 1958; Vol 29.

22 Saha AL. Integration of leprosy work with general health service. A must for effective leprosy control. Lepr in India, 1973; XLV: 2, 78-80.

${ }^{23}$ Hurerta R. View of a health administrator on leprosy control problem. Int J Lepr, 1968; 36: 3, 381-90.

24 Idris AA, Lolik P, Khan R, Benyousif A. WHO Chronicle, 1976; 30: 370-4.

25 Sudan: Democratic Republic of the Sudan (1976a) Primary Health Care Programme Southern Region 1977/78 - 1983/84 Juba.

26 Sudan: Democratic Republic of the Sudan (1976b) Primary Health Care, Eastern Northern, Central and Western Regions 1977/78 - 1983/84 Khartoum.

27 Warderkar RV. Integration of leprosy work into general medical services. Int J Lepr, 1969; 37: 2, 308-9.

28 Vai Danathan EP. Training of para-medical workers and their use in the leprosy programme. Int J Lepr, 1970; 38: 4, 433.

29 Ramu G. Integration of leprosy with general health service. Lepr in India, 1973; XIV, $4,262-6$.

30 Walter J. The present trends of anti leprosy chemotherapy and its practical implications. The 1st. International workshop of chemotherapy of leprosy in Asia Manila, Philippines 1977.

31 Torsned NA, Grevennikov PS. The forms of participation of local medical and prophylactic institutions in the control of leprosy in USSR. Int J Lepr, 1962; 30: 1.

32 Blanc MVJ. Integration of leprosy control at the onset of mass campaign in Indonesia. Lepr Rev, 1964a; 35: 205-9.

33 Blanc MVJ. An experiment of integration of leprosy control at the onset $=$ the area of Menganti. Lepr Rev, 1964b; 35: 211-216.

${ }^{34}$ Convit J. The campaign against leprosy in Venezuela. Int J Lepr, 1960; 28: 2, 167-70.

35 De Souza Lima L. Leprosy in the Americas. Int J Lepr, 1960; 28: 1, 20-65.

36 Sudan: Democratic Republic of the Sudan (1975) National Health Programme 1977/78 1983/84 Khartoum.

${ }^{37}$ Haidar AA. Leprosy in the Sudan - Geographical distribution and prevalence. Lepr Rev, $1975 ; 46: 219-22$.

38 Miquel R. Leprosy control in Thailand by the public health route. Int J Lepr, 1958; 26: $2,97$. 